\title{
Relation of CD30 expression to survival and morphology in large cell B cell lymphomas
}

\author{
L A Noorduyn, P C de Bruin, P van Heerde, $M$ M van de Sandt, G J Ossenkoppele, \\ C J L M Meijer
}

\begin{abstract}
Aims-To investigate whether CD30 expression is correlated with anaplastic morphology, and whether this correlated with a better survival in large cell $B$ cell lymphomas, as has been described for $T$ cell lymphomas.

Methods-CD30 expression was investigated using frozen sections in a series of 146 large cell B cell lymphomas. Clinical data and follow up information were collected from 25 lymphomas with strong CD30 expression, 30 lymphomas with partial CD30 expression, and a control group of 25 lymphomas which did not express CD30.
\end{abstract}

Results-Morphological distinction between anaplastic and non-anaplastic tumours was difficult. Of the cases with an anaplastic morphology, $50 \%$ were CD30 positive, as were $24 \%$ of the polymorphic centroblastic B cell lymphomas. Only $65 \%$ of the morphologically non-anaplastic tumours were completely CD30 negative. There was no difference in survival among patients with lymphomas expressing CD30 and those that did not. Patients with morphologically anaplastic $B$ cell lymphomas did not differ in their survivals from those with other high grade $B$ cell lymphomas. Clinical stage at presentation was the only variable that was significantly associated with survival.

Department of Pathology, Academic Medical Centre, Amsterdam L A Noorduyn

Department of Pathology, Free University Hospital, Amsterdam

P C de Bruin

C J L M Meijer

Netherlands Cancer Institute

$P$ van Heerde

Slotervaart Hospital, Amsterdam

M M van de Sandt

Department of

Haematology, Free

University Hospital,

Amsterdam

G J Ossenkoppele

Correspondence to:

Dr L A Noorduyn,

Department of Pathology,

Academic Medical Centre,

Meibergdreef $9,1105 \mathrm{AZ}$

Amsterdam, The

Amsterdam,

Accepted for publication

18 August 1993.
Conclusions-CD30 expression occurs

frequently in large cell B cell lymphomas and is poorly related to anaplastic morphology. Morphological distinction between anaplastic and non-anaplastic tumours is difficult. In contrast to $T$ cell lymphomas, CD30 positive B cell lymphomas do not show a relatively favourable clinical course. The results presented here raise serious doubts as to whether large cell $B$ cell lymphoma, based on the expression of CD30 or anaplastic morphology, can really be termed a separate entity.

(F Clin Pathol 1994;47:33-37)

In 1982 a monoclonal antibody that reacted selectively with Hodgkin and Reed-Sternberg cells was described by Schwab et al. ${ }^{1} \mathrm{Ki}-1$ (CD30) was subsequently shown to react with a number of large cell non-Hodgkin's lymphomas. ${ }^{2}$ Recently, it has been shown that $\mathrm{Ki}-1$ detects an antigen that is a member of the nerve growth factor receptor superfamily. ${ }^{3}$

Because these CD30 positive lymphomas seemed to present a specific histological picture, this group of lymphomas was called anaplastic large cell $(\mathrm{Ki}-1+)$ lymphoma, and was incorporated in the updated version of the Kiel classification among the high grade category of both $B$ cell and $T$ cell lymphomas. ${ }^{4}$ Several reports have described cases or series of these anaplastic large cell lymphomas, most of which have concentrated on the $T$ cell variety. ${ }^{25-16}$ Furthermore, several morphological subtypes have been described. ${ }^{5} 7$ 17-20

According to the updated Kiel classification, a lymphoma should not only express CD30, but also exhibit a so-called "anaplastic" morphology, to qualify as an anaplastic large cell lymphoma. Some studies mention the expression of CD30 in non-anaplastic lymphomas, ${ }^{27821}$ but none of these studies has systematically addressed the question of how frequently CD30 expression occurs in different morphological subtypes of large cell non-Hodgkin's lymphoma. In $\mathrm{T}$ cell lymphomas the relation between anaplastic morphology and CD30 expression seems to be fairly good, ${ }^{22}$ and CD30 expression is associated with a relatively benign clinical course. ${ }^{22} 23$ Whether this also holds true for B cell lymphomas is presently unknown.

\section{Methods}

In a pilot experiment of 44 large cell $B$ cell lymphomas CD30 expression, as demonstrated by $\mathrm{Ber}-\mathrm{H} 2^{24}$ on formalin fixed, paraffin wax embedded tissue, gave many false negative results when compared with frozen sections (fig 1). Therefore, we decided to use only those large cell lymphomas from which frozen tissue was available. We therefore collected 146 cases of large cell lymphoma from the files of the Comprehensive Cancer Centre Amsterdam (CCCA). Routinely stained slides (haematoxylin and eosin, reticulin, Giemsa, and periodic acid Schiff), and data on immunohistochemistry were also collected from all cases.

Staining with $\mathrm{Ber}-\mathrm{H} 2$ on frozen sections was performed according to standard procedures. Tumours were scored as positive $(+)$ if at least $50 \%$ of the tumour cells were stained clearly and dubious $(+/-)$ if less than $50 \%$ of the tumour cells were stained or if staining was weak. Morphological investigation of the tumours was performed with the help of routinely stained slides, without prior 


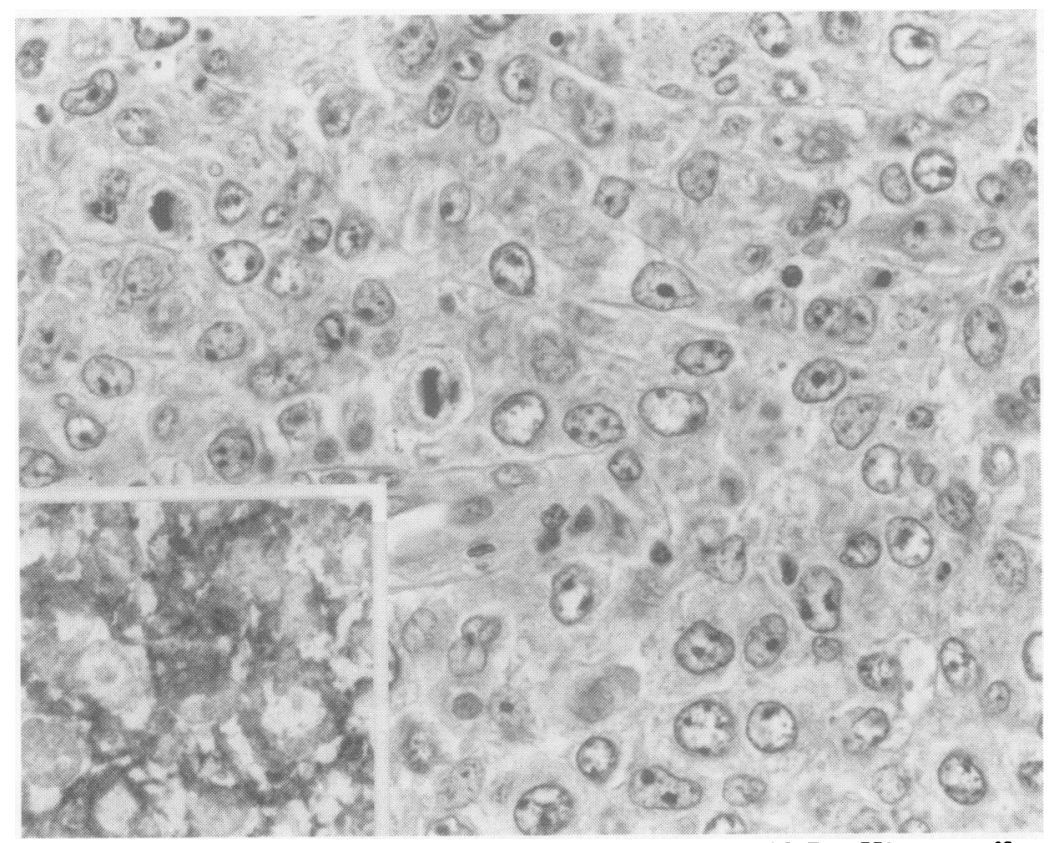

Figure 1 Polymorphic centroblastic B cell lymphoma. Staining with Ber-H2 on paraffin wax section is negative. Inset: staining with Ber-H2 on frozen section is positive.
Expression of CD30 (Ber-H2) in 146 large cell $B$ cell lymphomas, according to morphological subtype

\begin{tabular}{llll} 
CD30 & & & \\
\hline$+\quad \pm \quad$ & - & Total
\end{tabular}

B cell lymphomas

Follicular centroblastic Centrocytoid centroblastic Centroblastic Polymorphic centroblastic Immunoblastic Anaplastic

$\begin{array}{rrrr}2 & 5 & 7 & 14 \\ 2 & 10 & 29 & 41 \\ 2 & 5 & 22 & 29 \\ 9 & 7 & 21 & 37 \\ 2 & 1 & 6 & 9 \\ 8 & 2 & 6 & 16 \\ 25 & 30 & 91 & 146\end{array}$

$+>50 \%$ of the tumour cells positive; $\pm<50 \%$ of the tumour cells positive, or weak staining; - tumour cells negative.

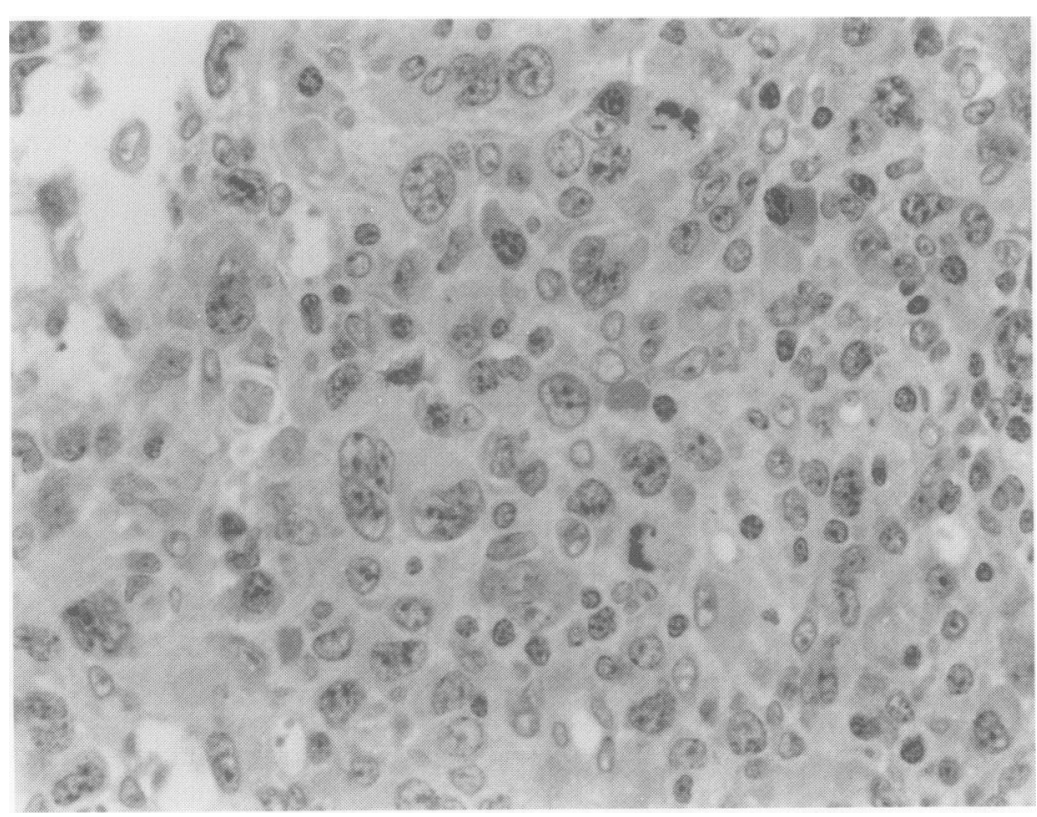

Figure 2 Anaplastic large cell lymphoma, B cell type (haematoxylin and eosin). knowledge of the results of $\mathrm{Ber}-\mathrm{H} 2$ staining.

Morphologically, the tumours were graded according to the updated Kiel classification. ${ }^{4}$ Tumours were scored as anaplastic if they met the criteria described by Suchi et al and Lennert. ${ }^{25}$ In short, anaplastic lymphomas were characterised by large or very large cells, with abundant cytoplasm, with large, often reniform or indented nuclei, and usually multiple, medium sized to large nucleoli. The tumour often showed an intrasinusoidal growth pattern.

Of the tumours that were scored as + or $+/-$, and from a control group of 25 tumours that were scored as -, clinical and follow up data were collected from the patients' records. This group of 25 patients whose tumours were completely CD30 negative was used as a control group for survival analysis. It included three patients with morphologically anaplastic, but immunohistochemically CD30 negative, tumours.

Statistical analysis of these data was performed with the help of a BMDP package.

\section{Results}

The numbers of positive tumours for each morphological subtype are shown in the table. In most tumours in the CD30 + category, over $80 \%$ of tumour cells were positive, and in the CD30 +/- category generally less than $20 \%$ were positive. Only a few tumours expressed CD30 in tumour cells close to the cutoff point of $50 \%$.

Of the B cell lymphomas that were morphologically scored as anaplastic (fig 2), $50 \%$ were positive with CD30, but of the immunoblastic and polymorphic centroblastic tumours, $22 \%$ and $24 \%$, respectively, were also positive. Even the other groups of large cell B cell lymphoma included cases which were positive with $\mathrm{CD} 30$, and a considerable percentage of these tumours showed partial or weak staining of the tumour cells. Only $65 \%$ of the morphologically non-anaplastic tumours were completely negative with CD30. In reviewing the morphology of the tumours, it was often difficult to differentiate anaplastic and non-anaplastic tumours. In particular, the distinction between polymorphic centroblastic lymphomas and immunoblastic B cell lymphomas on the one hand, and anaplastic large cell $B$ cell lymphomas on the other, was hard to make when the lymph node was completely invaded, and therefore, the characteristic intrasinusoidal growth pattern of anaplastic large cell lymphoma could not be seen. All these types of lymphoma were composed of large cells, usually with abundant cytoplasm, and anaplastic nuclei were detected in varying amounts in all of them. Therefore, the distinction was made by estimating the proportion of anaplastic nuclei, but we felt that placing these tumours in one category or another was often arbitrary.

Of the cases that expressed CD30, 25 patients were men, 10 of whom were in the CD30 + category, with 15 in the 
Figure 3 Survival curves of $C D 30+, C D 30+1-$, and $C D 30$ - large cell $B$ cell lymphomas. No significant difference was groups. seen between any of the

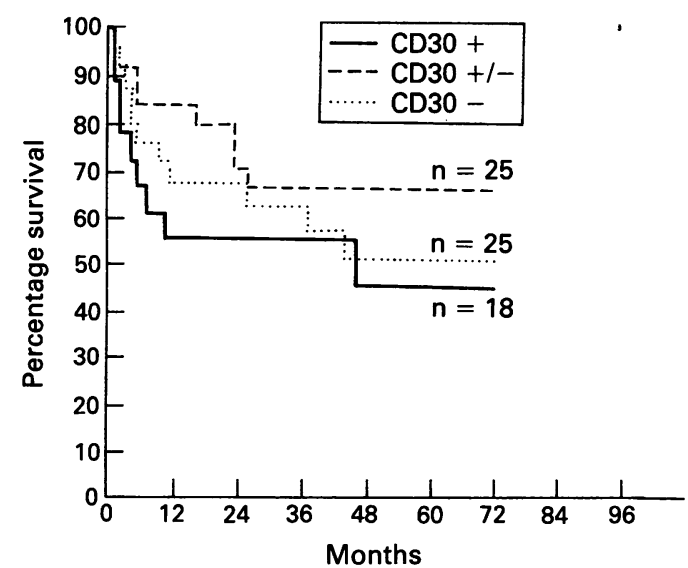

CD30 $+/-$ category. Thirty patients were women, 15 of whom were in the CD30 + category, with 15 in the CD30 +/- category. The patients were treated with surgical excision, radiotherapy, chemotherapy, or a combination of these treatments. Because the patients were treated in several institutions, and because treatment varied with time, they were not treated uniformly. We have no reasons, however, to assume that there were systematic differences in treatment between the groups of patients investigated.

Twelve patients in the CD30 + or CD30 $+1-$ group were excluded from the survival analysis, either because the clinical data could not be found $(n=10)$, or because they died of causes unrelated to their non-Hodgkin's lymphoma $(n=2)$. The survival analysis was performed on a total of 68 patients, 18 with CD30 + lymphomas, 25 with CD30 +/lymphomas, and a control group of 25 patients with CD30 - lymphomas. All those 68 patients had primary large cell $\mathrm{B}$ cell lymphoma, without evidence of a previous low grade lymphoma.

Nine of the 18 patients with $\mathrm{CD} 30+$ lymphomas $(50 \%)$ died of their disease, with a mean survival of nine months. The other nine patients were alive, with a mean follow up of 45 months. Nine of the 25 (36\%) patients with CD30 +/ - lymphomas died of their disease, with a mean survival of 20 months. The other 16 patients were alive, with a mean followup of 43 months. Eleven of the $25(44 \%)$ patients with CD30-

Figure 4 Survival curves of large cell $B$ cell lymphomas presenting with stage I or II, compared with stage III or IV disease. The difference is significant $(p=0 \cdot 01)$.

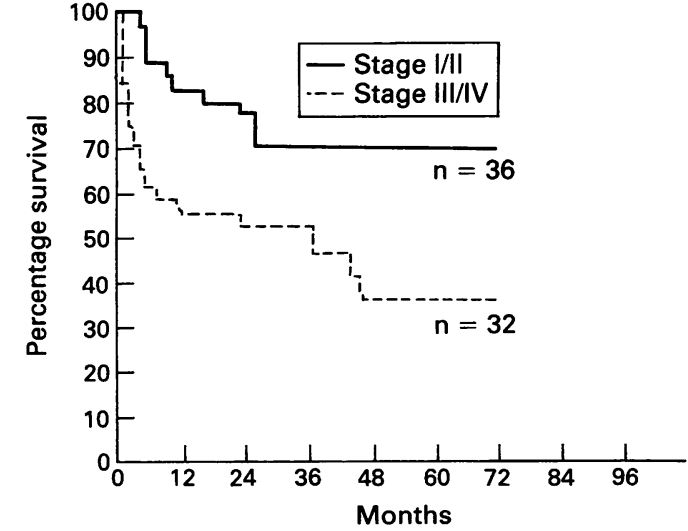

tumours died of their disease, with a mean survival of 13 months. The other 14 patients with CD30 - lymphomas were alive with a mean follow up of 47 months. There was no significant difference in survival between patients with $\mathrm{CD} 30+$ and those with CD30 - tumours $(p=0.55)$, nor was there a significant difference between CD30 +/ and CD30 - tumours $(p=0.41)$, or between CD30 + and CD30 + $1-$ tumours $(p=$ $0 \cdot 27$ ). A survival curve is shown in fig 3 .

Of the 12 patients with an anaplastic tumour morphology, six (50\%) had died of their lymphoma, with a mean survival of six months. The other patients had a mean follow up of 52 months. Of the 56 patients with a lymphoma without anaplastic morphology, $23(41 \%)$ had died, with a mean survival of 16 months. The other 33 patients were alive with a mean follow up of 44 months. Survival analysis did not show a significant difference between these groups of patients.

Of the seven patients with an anaplastic morphology in the CD30 + category, three $(43 \%)$ had died, with a mean survival of two months; the other four had a mean follow up of 49 months. Although this does not seem to indicate a different survival for this subgroup, the number of patients is clearly too small for definitive conclusions to be drawn.

Survival was also correlated with stage of disease at presentation. Eleven of the 36 (31\%) patients presenting with stage I or II disease died of their disease, with a mean survival of 19 months. The other 25 patients had a mean follow up of 45 months. Eighteen of the $32(56 \%)$ patients presenting with stage III or IV disease died of their disease, with a mean survival of 11 months. The other 14 patients had a mean follow up of 45 months. Survival analysis showed this difference to be significant $(p=0.01)$. A survival curve is shown in fig 4 .

\section{Discussion}

In our hands staining of B cell lymphomas with $B e r-\mathrm{H} 2$ on formalin fixed, paraffin wax embedded tissue seemed to be more variable than on frozen tissue. This discrepancy was not seen in $T$ cell lymphomas (data not shown). Other investigators have also reported difficulties in obtaining satisfying results with the $B e r-\mathrm{H} 2$ antibody on paraffin wax embedded material. ${ }^{27} 28$ Therefore, for diagnostic purposes, we think it is safer to use $\mathrm{Ber}-\mathrm{H} 2$ on frozen tissue.

Recently, it has been reported that $\mathrm{Ki}-1$ (CD30) detects two unrelated molecules, a 120 kilodalton membrane bound protein and a 57 kilodalton intracellular protein. ${ }^{29}$ In this report two Hodgkin's disease derived cell lines expressed both antigens, while a myeloma cell line expressed only the intracellular antigen. Therefore it might be possible that $\mathrm{CD} 30$ positive $\mathrm{B}$ cell lymphomas express one of the antigens, and that $\mathrm{CD} 30$ positive $T$ cell lymphomas the other, or both. If the antigen expressed by B cell lymphomas is less resistant to formalin fixation this could 
explain the discrepancy in the effect of fixation on CD30 expression between large cell $B$ cell lymphomas and large cell $T$ cell lymphomas.

CD30 expression in B cell lymphomas has received relatively little attention compared with CD30 expression in T cell lymphomas. Stein et $a l^{2}$ reported nine $\mathrm{CD} 30$ positive tumours in $62(15 \%)$ large cell B cell lymphomas, of which two showed an immunoblastic and seven an anaplastic morphology. Tashiro et $a l^{7}$ found two CD30 positive tumours in $45(4 \%)$ B cell lymphomas, but this study included small cell lymphomas. Several other studies only report the incidence of $\mathrm{CD} 30$ positive $\mathrm{B}$ cell lymphomas in relation to $T$ cell and non-B, non- $T$ cell lymphoma, 5689101421 but the generally low incidence indicates that the percentage of $\mathrm{B}$ cell lymphomas expressing CD30 is also low in these studies. The highest incidence of CD30 expression reported is by Pallesen, ${ }^{27}$ who found $\mathrm{CD} 30$ expression in 14 of 41 immunoblastic and 16 of $73(26 \%)$ centroblastic B cell lymphomas, while the number of anaplastic B cell lymphomas was not given. This last figure is in the same range as our findings, with 25 of $146(17 \%)$ large cell tumours showing strong CD30 expression, and $30(21 \%)$ showing partial or weak staining.

Several explanations can be given for our relatively high percentage of $\mathrm{CD} 30$ positive lymphomas. First, most studies reporting a predominance of $\mathrm{T}$ cell anaplastic large cell lymphomas do not state how they selected cases for staining with CD30, which means that a number of $\mathbf{B}$ cell anaplastic large cell lymphomas might have been missed. Moreover, as staining of B cell anaplastic large cell lymphoma with CD30 seems to be unreliable when performed on formalin fixed, paraffin wax embedded tissue, investigators who did not use frozen tissue will probably have underestimated the incidence of CD30 positive B cell lymphoma.

Finally, although we did not test the interand intraobserver variability in large cell $B$ cell lymphomas, we found that the morphological distinction between anaplastic tumours on the one hand and immunoblastic or polymorphic centroblastic tumours on the other was very difficult. This indicates that the inter- and intraobserver variability is probably high in the diagnosis of the $B$ cell variety of anaplastic large cell lymphoma and suggests that differences in morphological criteria and the inability to apply them consistently could account for a great deal of the differences in the relative reported prevalence of $B$ cell and $T$ cell anaplastic large cell lymphoma. It also does not support an attempt to subdivide anaplastic large cell lymphoma even further, as is advocated by some authors. ${ }^{5617}$

In this study, CD30 expression was present in all subtypes of B cell large cell lymphoma. The differences between polymorphic centroblastic and immunoblastic lymphomas on the one hand, and anaplastic lymphomas on the other, however, were not large. Furthermore, even in the morphologically anaplastic tumours, a considerable part of the tumours showed partial or weak staining, or none at all.

Because a favourable prognosis has been described for anaplastic CD30 positive $T$ cell lymphomas, ${ }^{22} 23$ we compared CD30 negative $(-)$ CD30 partially positive $(+/-)$, and CD30 positive $(+)$ large cell $B$ cell nonHodgkin's lymphomas, to detect a possible difference in clinical behaviour between those groups. We could not find any association between a favourable prognosis and CD30 expression.

None of the above mentioned studies has specifically addressed the prognosis of anaplastic large cell B cell non-Hodgkin's lymphoma, although several studies have described the clinical outcome of a limited number of patients. Tashiro et $a l^{7}$ reported one large cell and one small cell CD30 + B cell lymphoma; both patients were alive, with a mean follow up of 49 months. In the series of Chan $e t$ al $^{5}$ two patients died and one was alive after eight months of follow up. Bitter et $a l^{8}$ report two patients, who both died. Penny et al described six patients, ${ }^{16}$ who all were alive, but two patients were alive with disease, and three had a follow up of less than a year. Although these numbers are small, they seem to support our finding that CD30 + large cell B cell lymphoma does not have such a favourable prognosis.

These findings contrast with the situation in $\mathrm{T}$ cell lymphomas, which we have reported before. ${ }^{22}$ This indicates that there are obvious prognostic implications to establishing the $T$ cell or B cell lineage of a morphologically anaplastic non-Hodgkin's lymphoma. Research on CD30 expression in lymphomas should also clearly discriminate between $B$ cell and $T$ cell lymphomas.

In the present version of the Kiel classification $^{4}$ CD30 positive anaplastic lymphoma is incorporated in both the $\mathrm{B}$ cell and the $\mathrm{T}$ cell categories. In our view, in order to qualify as a clinicopathological entity, a subtype of lymphoma should originate from a particular type of lymphocyte, in a particular stage of lymphocyte development. It should show a distinct, reproducible histology, display a distinct clinical picture in terms of its patient population, localisation, clinical course, or response to treatment, or, if possible, show a combination of these features. Previous studies have indicated that the $T$ cell variety of large cell anaplastic CD30 positive lymphoma has a distinctive morphology, ${ }^{22}$ and that its recognition is histologically reproducible. ${ }^{30}$ Furthermore, primary nodal and primary cutaneous CD30 positive $T$ cell lymphomas run a relatively benign clinical course. For large cell B cell lymphomas, however, the situation is entirely different. These tumours are morphologically not well demarcated from other large cell B cell lymphomas, and correlation between CD30 expression and morphology is poor. Neither CD30 expression, nor anaplastic morphology was correlated 
with a difference in survival in the present study.

These clinicopathological data raise the question as to whether $\mathrm{CD} 30+$ anaplastic large cell lymphomas of the $B$ cell variety should be considered a separate clinicopathological entity. Of course, one study and a limited number of patients do not preclude slight differences. In particular, in this study the number of patients with CD30 + tumours that were also morphologically anaplastic was too small for definite conclusions to be drawn. We feel, however, that our results raise serious doubts about whether CD30 expression and anaplastic morphology do really define a separate entity in large cell B cell lymphomas, as they do in large cell $\mathrm{T}$ cell lymphomas.

This study was supported by the Comprehensive Cancer Centre, Amsterdam.

1 Schwab U, Stein H, Gerdes J, et al. Production of a monoclonal antibody specific for Hodgkin and monoclonal antibody specific, for Hodgkin and Sternberg-Reed cells of Hodgkin's disease and

2 Stein H, Mason DY, Gerdes J, et al. The expression of the Hodgkin's disease associated antigen $\mathrm{Ki}-1$ in reactive Sternberg cells and histiocytic malignancies are derived from activated lymphoid cells. Blood 1985;66:848-58.

3 Durkop H, Latza U, Hummel M, Eitelbach F, Seed B Stein $\mathrm{H}$. Molecular cloning and expression of a new member of the nerve growth factor receptor family that is characteristic for Hodgkin's disease. Cell 1992;68: $421-7$.

4 Stansfeld AG, Diebold J, Kapanci Y, et al. Updated Kiel classification for lymphomas. Lancet 1988;i:292-3.

9 Chan JKC, Ng CS, Hui PK, et al. Anaplastic large cell Ki1 lymphoma. Delineation of two morphological types. 1 lymphoma. Delineation of

6 Chott A, Kaserer K, Augustin I, et al. Ki-1-positive large cell lymphoma. A clinicopathologic study of 41 cases. Am $\mathcal{F}$ Surg Pathol 1990;14:439-48

7 Tashiro K, Kikuchi M, Takeshita M, Yoshida T Ohshima K. Clinicopathological study of Ki-1 positive lymphomas. Path Res Pract 1989;185:461-7.

8 Bitter MA, Franklin WA, Larson RA, et al. Morphology in $\mathrm{Ki}-1$ (CD30)-positive non-Hodgkin's lymphoma is correlated with clinical features and the presence of unique chromosomal abnormality, $\mathrm{t}(2 ; 5)(\mathrm{p} 23 ; 35) \mathrm{Am} \mathcal{f}$ unique chromosomal abnormal
Surg Pathol 1990;14:305-16.

9 Agnarsson BA, Kadin ME. Ki-1 positive large cell lymphoma. A morphologic and immunologic study of 19 phoma. A morphologic and immunologic

10 O'Connor NTJ, Stein H, Gatter KC, et al. Genotypic analysis of large cell lymphomas which express the Ki-1 antigen. Histopathology 1987;11:733-40.

11 Oka K, Mori N, Kojima M, Iijima T, Hanada T, Tsuchida M. Childhood $\mathrm{Ki}-1$ lymphoma. A report of two cases. Arch Pathol Lab Med 1989;113:998-1002.
12 Schnitzer B, Roth MS, Hyder DM, Ginsburg D. Ki-1 lymphomas in children. Cancer 1988;61:1213-21.

13 Falini B, Pileri S, Stein H, et al. Variable expression of leucocyte-common (CD45) antigen in CD30 (Ki-1)positive anaplastic large-cell lymphoma: Implications for the differial diagnosis between lymphoid and nor lymphoid malignancies. Hum Pathol 1990;21:624-9.

14 Ohshima K, Kikuchi M, Masuda Y, et al. Genotypic and immunophenotypic analysis of anaplastic large cell immunophenotypic analysis of anaplastic large cell 186:582-8

15 Nakamura S, Takagi N, Kojima $M$, et al. Clinicopathologic study of large cell anaplastic lymphoma (Ki-1-positive large cell lymphoma) among the Japanese. Cancer 1991;68:118-29.

16 Penny RJ, Blaustein JC, Longtine JA, Pinkus GS. Ki-1positive large cell lymphomas, a heterogenous group of neoplasms. Cancer 1991;68:362-73.

17 Pileri S, Falini B, Delsol G, et al. Lymphohistiocytic Tcell lymphoma (anaplastic large cell lymphoma CD30 $+/ \mathrm{Ki}-1+$ with a high content of reactive histiocytes. Histopathology 1990;16:383-91.

18 Le Tourneau A, Audouin J, Diebold J, Pujade-Lauraine E, Bernadou A. Large anaplastic cell $\mathrm{Ki}-1$ positive malignant lymphoma with peculiar endocytotic vacuoles. Path Res Pract 1990;186:784-92.

19 Chan JKC, Buchanan R, Fletcher CDM. Sarcomatoid variant of anaplastic large cell lymphoma. Am $\mathcal{f}$ Surg Pathol 1990;14:983-8.

20 Noorduyn LA, Van Heerde P, Meyer CJLM. Cytology of Ki-1 (CD-30) positive large cell lymphoma. Cytopathology 1990;1:297-304.

21 Piris M, Brown DC, Gatter KC, Mason DY. CD30 expression in non-Hodgkin's lymphoma. Histopathology 1990;17:211-18.

22 De Bruin PC, Noorduyn LA, Van der Valk P, et al. Noncutaneous T-cell lymphomas: recognition of a lymcutaneous T-cell lymphomas: recognition of a lymfavorable prognosis. Cancer 1993;71:2604-12.

23 Beljaards RC, Meijer CJLM, Scheffer E, et al. Prognostic significance of $\mathrm{CD} 30(\mathrm{Ki}-1 / \mathrm{Ber}-\mathrm{H} 2)$ expression in primary cutaneous large-cell lymphomas of T-cell origin. A clinicopathologic and immunohistochemical study in 20 patients. Am $\mathcal{F}$ Pathol 1989;135:1169-78.

24 Schwarting R, Gerdes J, Dürkop H, Falini B, Pileri S, Stein H. Ber-H2: A new anti-Ki-1 (CD30) monoclonal antibody directed at a formol-resistant epitope. Blood 1989;74:1678-89.

25 Suchi T, Lennert K, Tu L-Y, et al. Histopathology and immunohistochemistry of peripheral T cell lymphomas: immunohistochemistry of peripheral T cell lymphomas: a proposal for the

26 Grosszelliges anaplastisches Lymphom vom T-Typ $(\mathrm{Ki}-1+)$. In: Lennert K, Feller AC. Histopathologie der Non-Hodgkin-lymphome. Berlin: Springer Verlag 1990 217-31.

27 Pallesen G. The diagnostic significance of the CD30 (Ki-1) antigen. Histopathology 1990;16:409-13.

28 Hutchison RE, Fairclough DL, Holt $\mathrm{H}$, et al. Clinical significance of histology and immunophenotype in childhood diffuse large cell lymphoma. Am $\mathcal{f}$ Clin Pathol 1991;95:787-93.

29 Rhode $D$, Hansen $H$, Hafner $M$, et al. Cellular localizations and processing of the two molecular forms of the tions and processing of the two molecular forms of the kinase Ki-1/57 occurs in the nucleus. Am 7 Pathol kinase $\mathrm{Ki}-1 / 57$ \%

30 Hastrup N, Hamilton-Dutoit S, Ralfkiaer E, Pallesen G. Peripheral T-cell lymphomas: an evaluation of reproducibility of the updated Kiel classification. Histopathology 1991;18:99-105. 